\title{
The Effect of using Artificial Intelligence on Performance of Appraisal System: A Case Study for University of Jeddah Staff in Saudi Arabia
}

\author{
Ahmed Alrashedi \\ College of Business \\ University of Jeddah, Saudi Arabia \\ aalrashde@uj.edu.sa
}

\author{
Maysam Abbod \\ Department of Electronic \& Computer Engineering \\ Brunel University London \\ maysam.abbod@brunel.ac.uk
}

Abstract - Despite the interest of developed countries in relying on artificial intelligence in the performance of their work, developing countries are at the beginning of this path. The researcher has noted that the use of modern technologies, especially artificial intelligence, did not give the necessary attention in government business and many private sector companies, so it was necessary to draw attention to the importance of using it to develop all businesses. This study focuses on clarifying the importance of using artificial intelligence (AI) technology in the process of evaluating the employee's performance to increase the effectiveness of performance appraisal for all organisational levels to make strategic decisions which affect the objectives of the organisation. This study has used a questionnaire that looked at participants' views and attitudes towards technology and its usefulness in the appraisal process. Knowing the opinions of employees and their supervisors will enable to demonstrate the need to use AI to raise the efficiency of the performance appraisal system and develop its processes for the employee's benefits and the general interest at the organisation. Most of the answers were between agree and strongly agree, and on the other side, there was a very small percentage that did not believe the importance of using artificial intelligence in works, and this may be due to their feeling of resisting change and the desire to work a way they used to. This paper begins by providing demographic details and background information on the participants, followed by an examination of the reliability of the extracted factors/metrics. The extracted factors will then be described individually using general descriptive statistics (such as repetition percentages) to look at their respective elements and see the level of the agreement created by the participant. Following this descriptive part of the analysis, this paper seeks to conduct an in-depth analysis of the results using various inferential statistics to test group differences using demographic and background details of the participants (e.g. age, gender, education). This study investigates the impact of the use of AI on the performance appraisal model, and to examine the effect of AI on the technology adoption.

Keywords- Artificial Intelligence; performance appraisal; software benefit; technology adoption.

\section{INTRODUCTION}

Performance appraisal is an essential task for any manager to determine the performance of his subordinates and their achievement of business objectives (Klimoski \& London, 1974). It imposes physical and psychological effort on managers having to investigate the factors that influence the employee performance (Antunes et al., 2012). They found that there are five factors with positive impact on performance appraisal system, namely: implementation process, interpersonal relationships, rate accuracy, informational factors, and employee attitudes. in addition, there are two evaluation process' approaches, one is technical regarding the accuracy and comprehensiveness of employee-related information from multiple locations within the organization, and the other is social regarding employee acceptance of evaluation results (Arraiz, 2017). Technically, an organisation can use artificial intelligence (AI) to collect data from multiple sites within the organisation on how an employee perform his work. By linking these available data, line managers could come up with appropriate and objective proposals that predict individual performance and help the organisation to make negative or positive decisions regarding employee's behaviours. Furthermore, on the social side, employees will be more convinced and confident with the AI system due to its accuracy and objective in comparison to traditional assessments (Jewels, 2006).

Performance appraisal is essential for both employees and organisation. The employee would know the exact level of their performance because self-assessment can be inaccurate. On the other hand, the organisation would be aware of the performance level of its staff to decide who requires training to improve and develop his performance or learn new skills for his work. Furthermore, evaluation results are essential for determining who is being penalised, rewarded or transferred to another job that fits with his abilities. Both sides can be beneficiaries. Orlikowski (2000) has argued that in order for organisations to achieve competitive advantages, they must keep abreast of society technological developments that enable them to develop their business, so it is necessary to utilize technologies such as AI to develop and improve the performance appraisal system and encourage employees by providing accurate and honest results of the evaluation system (Sholihin, 2013). 
The reliance on AI technology will help to obtain a vast amount of information related to the employee by logging previous evaluations and views of the former and current managers, which gives an integrated employees picture; therefore, the assessment will be written in an accurate and objective way. The results of the evaluation should be evaluated, analysed and reviewed for all staff to categorise available competencies based on business needs for all departments in the organisation (Daoanis, 2012).

This study investigates the impact of the use of AI on the performance of the appraisal model, and to examine the effect of technology adoption on the use of artificial intelligence. See Figure 1.

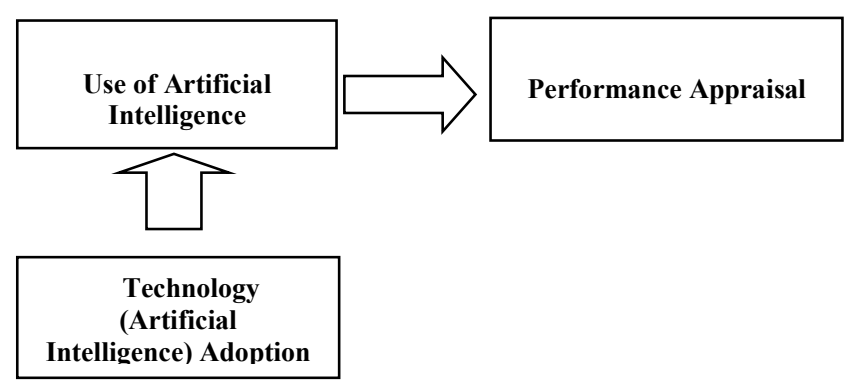

Figure 1: An image showing technology adoption that affects the use of AI which affect performance appraisal.

\section{LITERATURE REVIEW}

The performance appraisal system is one of the most critical systems to any organization to know the level of employees' performance and their ability to achieve its goals with the highest efficiency to be able to face its competitors either in the local or global market. Orlikowski ( 2000) has argued that In order to achieve competitive advantages, organizations must keep abreast of technological developments in society that enable them to develop their businesses and implementers, so it was necessary to take advantage of the technology of artificial intelligence to develop and improve the performance evaluation system and to encourage employees to feel the accuracy and fairness of the evaluation system (Sholihin, 2013).

\subsection{Artificial Intelligence}

AI is a computer algorithm has the capability to learn (Kornienko et al., 2015). It is a system that simulates complex problem solving based on its capabilities of symbolic thinking, flexibility and explanation (Metaxiotis et al., 2003). Rodríguez, Hermosillo \& Lara (2012) have defined AI as a scientific field designed to simulate the behaviour of the human brain by devices, both of them are considered as an information processing machines. Rodríguez, Hermosillo, Lara (2012); Masum et al. (2018), have proposed a framework of intelligent human resources information based on the use of hybrid AI tools such as automated learning and knowledge-based approaches so, that data can be collected without human intervention, stored, accurately summarized, processed to derive new information to support the decision-making process. Dependence on AI will accomplish business more quickly, correctly and cost less, leading to the competitive advantage of the organization. It will also assist human resources management in planning, reporting, assessing policies, forecasting needs, training and forecasting staff performance, all those without human intervention. It is possible to say that $\mathrm{AI}$ is a new generation of technology that will make the perfect machine capable of simulating human behaviour entirely and whose components are small (Agrawal, et al., 2019).

It is known that AI is not about one technology; it is a set of different techniques to obtain high-quality products and services in less time and cost. Human resources professionals can take advantage of these technologies for improving the system such as recruitment, selection, training, development, performance appraisal, compensation and reward (Jain, 2017). Brynjolfsson \& Hitt (2000) have discussed how computers contribute to business performance and economic growth. It is not vital to use technology like others, but it is crucial to take advantage of it (D'Amico, 2016).

Kolbjørnsrud, Amico \&Thomas (2016) have believed that Artificial intelligence will soon be able to do administrative tasks that consume more than half of managers time in jobs, coordination control and evolution employees will be faster and better and at a lower cost. They have also convinced that managers who deal with AI such as researcher, explorer, analyst, evaluator, in addition to giving them different scenarios to solve problems. All these will make employees trust his evolution. By using smart technology, the system will receive a tremendous amount of information about the staff, which can be viewed in one place with accuracy and speed that is unexpected at the least time and cost. It is much better than traditional methods. Choi, Lee \& Yoo (2010) have found that the system of mutual memory helps to share knowledge among bosses and between employees and their bosses which positively would affect organizational performance.

\subsection{Performance Appraisal}

Antunes et at, (2012) have viewed factors influencing employee performance appraisal system. They found that there are five factors that have positive or negative impact on performance appraisal system, which are implementation process, interpersonal relationships, rate accuracy, informational factors, and employee attitudes. Iqbal et al. (2013) have found that because employees are the most critical resource, they must be developed and improved performance to achieve the organizational goals, and therefore, human resource management through managers should measure staff performance annually and frequently to ensure their efficiency (Klimoski \& London, 1974). 
Because of the lack of evaluator's managerial skills, this will negatively affect the outcome of the evaluation and lose its impact on employees, the organization has to rely on AI for performance appraisal. Jawahar (2010) has argued that organizations can design performance appraisal systems per the legal regulation of organizational framework that makes it necessary to use an accurate, comprehensive, transparent and objective scientific method. These features will only be available in AI. This will be able to make the best decisions about the employees' performance. These decisions can be trusted and easy for employees to accept and managers to discuss their findings objectively with staff. These decisions will be based on all information related to team past and current performances which make them objective and acceptable to all employees. They also can reduce doubts about their accuracy and relevance and will be better than if it relies solely on a traditional approach that depends only on supervisor's ability to remember all bad or good situations to write employee evaluation (Arraiz, 2017).

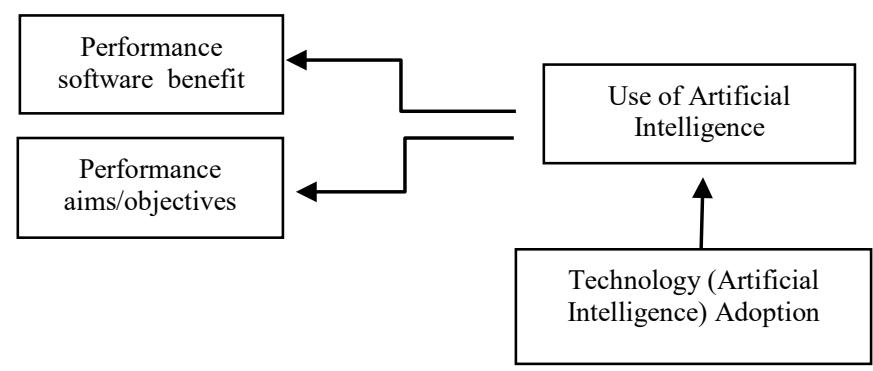

Figure 2: Research hypotheses and research model.

\section{RESEARCH HYPOTHESES \& RESEARCH MODEL}

This study tests the following hypotheses (see Figure 2): H1: Technology (AI) Adoption will positively affect the Use of AI.

H2: Use of AI will positively affect Performance software benefit of performance appraisal.

H3: Use of AI will positively affect Performance aims/objectives of performance appraisal.

\section{Procedures AND DATA COLlection}

A total of 339 employees were randomly selected from universities and companies in Saudi Arabia, namely King Abdulaziz University, King Khalid University, Taif University, Umm Al-Qura University, Saudi Aramco, Saudi Arabian Airline. There were 113 females and 226 males. The aggregate number of participants was aged between 18 to 55 years old.

The questionnaire was constructed to cover three distinct dimensions, namely Performance Appraisal (11 items), Utilisation of Artificial intelligence (11 items) and Technology Adoption factors (8 items). The aspects were constructed in a way to answer the research questions/aims asset declared in the introduction. Employee responses were obtained using a 4-point Likert-type scale where one = strongly disagree, and $4=$ strongly agree.

\section{DATA COLLECTION}

\subsection{Participants' Demographic Data}

This section provides a general description of the background and demographic characteristics of the sample used in this study. Overall 339 took part, $66.6 \%$ were males, and $33.3 \%$ were females. Their education and qualification varied where slight majority of the participants had $\mathrm{PhD}$ level of skill $(34.3 \%)$ followed by bachelor's degree $(30.2 \%)$, and $27.3 \%$ stated they have a master's degree. Only $2.9 \%$ had a diploma level of qualification, and 5.3\% explained they had completed high school level of education. As of the organisation they work for the majority of $66.9 \%$ work in the government sector, and $33.1 \%$ worked in the private sector. Finally, participants' nationalities varied were the vast majority of $83 \%$ were Saudis, and $17 \%$ were non-Saudis. Egyptians (10\%) and Tunisians (3.8\%) were the two main nationalities represented other than Saudis. Table 1 shows the frequencies and the percentages of all variables.

\subsection{Reliability}

Cronbach's Alpha test was conducted to measure the consistency in answers across items within each of the dimensions (internal reliability) and each of the factors produced following Factor Analysis. This test enables the research to judge how reliable each of the scales is, i.e. how consistently items measure for the same thing. Cronbach's alpha is a coefficient that ranges between 0 and 1 in size, where value close to 0.70 or above are considered acceptable. As can be observed from Table 2, all dimensions can be regarded as reliable.

Table 2: Cronbach's alpha as a measure for internal reliability.

\begin{tabular}{|c|c|c|}
\hline Dimension/scale & Items & Cronbach's Alpha \\
\hline Performance appraisal & 11 & 0.815 \\
\hline Performance and Software Benefit & 6 & 0.793 \\
\hline Performance Aims/objectives & 5 & 0.755 \\
\hline The utilisation of Artificial Intelligence & 11 & 0.910 \\
\hline Technology Adoption Factors & 8 & 0.903 \\
\hline
\end{tabular}

VI. RESULTS AND ANALYSIS

\subsection{The Impact Technology Adoption Factors on the Use of AI}

Linear regression was conducted to examine the effects of technology adoption factors on use of AI. Table 3 shows that a significant relationship exists between the dependent variable Use of Artificial intelligence and the independent variables Technology (AI) Adoption, where $F=276.853$ and P-value $<0.001$ (the coefficient of determination being $45.0 \%$ ), but that high significant relationship exists thereof with technology adoption factors and the use of AI. 


\subsection{Impact of Use of Artificial intelligence on Performance Appraisal}

Two factors were analysed, namely performance software benefits, and performance aim/objectives. For factor 1 , linear regression was conducted to examine the impact of using AI on performance software benefit. The results presented in Table 4 show that a significant relationship exists between the dependent variable performance software benefit and the independent variables use of Artificial intelligence, where $\mathrm{F}=90.075$ and $\mathrm{P}$-value $<0.001$ (the coefficient of determination being 21.0) which proves the Hypothesis $\mathrm{H} 2$ is actual "Use of AI will positively affect Performance software benefit of Performance Appraisal".

Table 1: General demographic and background details of the participants.

\begin{tabular}{|c|c|c|c|c|c|c|c|c|}
\hline Age & $\mathrm{n}$ & $\%$ & Gender & $\mathrm{n}$ & $\%$ & Nationality & $\mathrm{n}$ & $\%$ \\
\hline $18-25$ & 10 & 2.9 & Male & 226 & 66.3 & Saudi & 283 & 83.0 \\
\hline $26-30$ & 22 & 6.5 & Female & 113 & 33.1 & Egyptian & 34 & 10.0 \\
\hline $31-35$ & 50 & 14.7 & Missing & 2 & 0.6 & Jordanian & 4 & 1.2 \\
\hline $36-40$ & 66 & 19.4 & Education & $\mathrm{n}$ & $\%$ & Tunisian & 13 & 3.8 \\
\hline $41-45$ & 45 & 13.2 & High School & 18 & 5.3 & Sudanese & 3 & 0.9 \\
\hline $46-50$ & 60 & 17.6 & Diploma & 10 & 2.9 & Palestinian & 1 & 0.3 \\
\hline$>50$ & 88 & 25.8 & Bachelor & 103 & 30.2 & Lebanese & 1 & 0.3 \\
\hline & & & Master & 93 & 27.3 & Missing & 2 & 0.6 \\
\hline & & & PhD & 117 & 34.3 & Grouped Nationality & $\mathrm{n}$ & $\%$ \\
\hline Organisation & $\mathrm{n}$ & $\%$ & & & & Saudi & 283 & 83.0 \\
\hline Government & 226 & 66.3 & & & & Non-Saudi & 56 & 17 \\
\hline Private & 113 & 33.1 & & & & Total & 339 & 100 \\
\hline
\end{tabular}

Table 3: Linear Regressing between dependent variable "use of technology" and independent variable "AI technology adoption" in the study.

\begin{tabular}{|c|c|c|c|c|c|c|c|c|}
\hline & \multicolumn{2}{|c|}{$\begin{array}{c}\text { Unstandardized } \\
\text { Coefficients }\end{array}$} & $\begin{array}{c}\text { Standardized } \\
\text { Coefficients }\end{array}$ & $\mathbf{t}$ & Sig. & \multicolumn{2}{|c|}{ ANOVA } & $\mathbf{R}^{2}$ \\
\cline { 2 - 7 } & B & $\begin{array}{c}\text { Std. } \\
\text { Error }\end{array}$ & Beta & & F & P-value & \\
\hline Constant & 1.656 & 0.165 & & 10.009 & 0.000 & \multirow{2}{*}{276.853} & $<0.001$ & 0.450 \\
\hline $\begin{array}{l}\text { Technology (AI) } \\
\text { Adoption Factors }\end{array}$ & 0.626 & 0.038 & 0.670 & 16.639 & 0.000 & & & \\
\hline
\end{tabular}

Table 4: Linear regressing between dependent variable "performance software benefit" and independent "use of AI" variable in the study.

\begin{tabular}{|c|c|c|c|c|c|c|c|c|}
\hline & \multicolumn{2}{|c|}{$\begin{array}{l}\text { Unstandardized } \\
\text { Coefficients }\end{array}$} & \multirow{2}{*}{$\begin{array}{c}\begin{array}{c}\text { Standardized } \\
\text { Coefficients }\end{array} \\
\text { Beta }\end{array}$} & \multirow{2}{*}{$\mathbf{t}$} & \multirow{2}{*}{ Sig. } & \multicolumn{2}{|c|}{ ANOVA } & \multirow{2}{*}{$\mathbf{R}^{2}$} \\
\hline & B & $\begin{array}{c}\text { Std. } \\
\text { Error }\end{array}$ & & & & $\mathbf{F}$ & P-value & \\
\hline Constant & 2.681 & 0.192 & & 13.937 & 0.000 & \multirow{2}{*}{90.075} & \multirow{2}{*}{$<0.001$} & \multirow{2}{*}{0.210} \\
\hline Use of AI & 0.413 & 0.044 & 0.458 & 9.491 & 0.000 & & & \\
\hline \multicolumn{6}{|c|}{ Dependent Variable: Performance software benefit (Factor 1) } & & & \\
\hline
\end{tabular}

Table 5: Linear regression between Dependent Variable (Performance aims/objectives) and Independent (Use of AI) variables in the study.

\begin{tabular}{|c|c|c|c|c|c|c|c|c|}
\hline & \multicolumn{2}{|c|}{$\begin{array}{l}\text { Unstandardized } \\
\text { Coefficients }\end{array}$} & \multirow{2}{*}{$\begin{array}{c}\begin{array}{c}\text { Standardized } \\
\text { Coefficients }\end{array} \\
\text { Beta }\end{array}$} & \multirow{2}{*}{ t } & \multirow{2}{*}{ Sig. } & \multicolumn{2}{|c|}{ ANOVA } & \multirow{2}{*}{$\mathbf{R}^{2}$} \\
\hline & B & $\begin{array}{c}\text { Std. } \\
\text { Error }\end{array}$ & & & & $\mathbf{F}$ & P-value & \\
\hline Constant & 0.950 & 0.215 & & 4.421 & 0.000 & \multirow{2}{*}{234.214} & \multirow{2}{*}{$<0.001$} & \multirow{2}{*}{0.409} \\
\hline Use of AI & 0.745 & 0.049 & 0.639 & 15.304 & 0.000 & & & \\
\hline \multicolumn{6}{|c|}{ aims/objectives } & & & \\
\hline
\end{tabular}

For factor 2, linear regression was conducted to examine the impact of the use of AI on performance aims/objectives.
Table 5 shows that a significant relationship exists between the dependent variable Performance aims/objectives of the 
determination being $40.9 \%$ ), which supports that the hypothesis H3 is valid" Use of Artificial intelligence will positively affect Performance aims/objectives of Performance Appraisal".

Table 6: Summary of hypothesis testing.

\begin{tabular}{|c|c|c|}
\hline Hypothesis & Specification & Results \\
\hline H1 & $\begin{array}{c}\text { AI technology adoption positively } \\
\text { affect the use of AI }\end{array}$ & $\begin{array}{c}\text { Supported }(\beta=0.626, \\
\mathrm{p}<0.01)\end{array}$ \\
\hline H2 & $\begin{array}{c}\text { Use of AI positively affect } \\
\text { performance software benefit of } \\
\text { performance appraisal }\end{array}$ & $\begin{array}{c}\text { Supported }(\beta=0.413, \\
\mathrm{p}<0.01)\end{array}$ \\
\hline H3 & $\begin{array}{c}\text { Use of AI positively affect } \\
\text { performance aims/objectives of } \\
\text { Performance Appraisal }\end{array}$ & $\begin{array}{c}\text { Supported }(\beta=0.745, \\
\mathrm{p}<0.01)\end{array}$ \\
\hline
\end{tabular}

\section{CONCLUSION \& DISCUSSION}

This study to investigate the impact of Use of AI on Performance software benefit and Performance aims/objectives, also to examine the effects of AI technology adoption on use of AI. In summary, as shown in Table 6 , the results of the linear regression analyses confirmed the three hypotheses. Use of AI has high significant effect on Performance software benefit and on Performance aims/objectives also Technology (AI) Adoption had the most definite impact on the Use of AI. This study has shown that, Technological Artificial Intelligence Role in Raising the Efficiency of Performance Appraisal System.

Based on the results of this study which have showed positive impact of AI on the performance appraisal program, the researcher is currently working on designing a program that helps human resources management to evaluate employees' performance in order to take advantage of artificial intelligence in obtaining an integrated image of employee to include all the relevant information and data since their entry to company until the present, with the ability to predict future career that make benefit to both company and employees.

\section{REFERENCES}

[1] Agrawal, A., Gans, J.S. and Goldfarb, A., 2019. Artificial intelligence: the ambiguous labour market impact of automating prediction. Journal of Economic Perspectives, 33(2), pp.31-50.

[2] Antunes, P., Herskovic, V., Ochoa, S.F. and Pino, J.A., 2012. Structuring dimensions for collaborative systems evaluation. $A C M$ Computing Surveys (CSUR), 44(2), p.8.

[3] Arrays, J.I., 2017. Electronic performance measurement systems: feasibility of dynamic performance measurement systems: a case study (Doctoral dissertation, Nottingham Trent University).
[4] Baker, J., 2012. The technology-organization-environment framework. Information systems theory (pp. 231-245). Springer, New York, NY.

[5] Boachie-Mensah, F.O. and Seidu, P.A., 2012. Employees' perception of performance appraisal system: A case study. International Journal of Business and Management, 7(2), p. 73.

[6] Brynjolfsson, E. and Hitt, L.M., 2000. Beyond computation: Information technology, organizational transformation and business performance. Journal of Economic Perspectives, 14(4), pp. 23-48.

[7] Choi, S.Y., Lee, H. and Yoo, Y., 2010. The impact of information technology and transactive memory systems on knowledge sharing, application, and team performance: a field study. MIS quarterly, pp.855-870.

[8] D'Amico, Emanuele, Carmela Leone, Tumani Hayrettin, and Francesco Patti. "Can we define a rehabilitation strategy for cognitive impairment in progressive multiple sclerosis? A critical appraisal." Multiple Sclerosis Journal 22, no. 5 (2016): 581-589.

[9] Daoanis, L.E., 2012. Performance appraisal system: it's implication to employee performance. International Journal of Economics and Management Sciences, 2(3), pp. 55-62.

[10] Hunter, J.E., 1983. A causal analysis of cognitive ability, job knowledge, job performance, and supervisor ratings. Performance measurement and theory, 257, p. 266.

[11] Iqbal, Nadeem, Naveed Ahmad, Zeeshan Haider, Yumna Batool, and Qurat Ul-ain. "Impact of performance appraisal on employee's performance involving the moderating role of motivation." Oman Chapter of Arabian Journal of Business and Management Review 34, no. 981, (2013): 1-20.

[12] Jawahar, I.M., 2006. Correlates of satisfaction with performance appraisal feedback. Journal of Labor Research, 27(2), pp.213-236.

[13] Jain, V.K., Kumar, S. and Fernandes, S.L., 2017. Extraction of emotions from multilingual text using intelligent text processing and computational linguistics. Journal of computational science, 21, pp. 316-326.

[14] Klimoski, R.J. and London, M., 1974. Role of the rater in performance appraisal. Journal of Applied Psychology, 59(4), p. 445.

[15] Kornienko, A.A., Kornienko, A.V., Fofanov, O.B. and Chubik, M.P., 2015. Knowledge in artificial intelligence systems: searching the strategies for application. Procedia-Social and Behavioral Sciences, 166, pp. 589-594.

[16] Kolbjørnsrud, V., Amico, R. and Thomas, R.J., 2016. How artificial intelligence will redefine management. Harvard Business Review, 2.

[17] Masum, A.K., Beh, L.S., Azad, A.K. and Hoque, K., 2018. Intelligent Human Resource Information System (i-HRIS): A Holistic Decision Support Framework for HR Excellence. International Arab Journal of Information and Technology, 15(1), pp. 121-130.

[18] Metaxiotis, K., Karagiannis, A., Askounis, D. and Psarras, J., 2003. Artificial intelligence in short term electric load forecasting: a stateof-the-art survey for the researcher. Energy Conversion and Management, 44(9), pp. 1525-1534

[19] Orlikowski, W.J., 2000. Using technology and constituting structures: A practise lens for studying technology in organizations. Organization Science, 11(4), pp. 404-428.

[20] Rodríguez, D., Hermosillo, J. and Lara, B., 2012. Meaning in artificial agents: The symbol grounding problem revisited. Minds and Machines, 22(1), pp. 25-34.

[21] Sholihin, M., 2013. How does procedural fairness affect performance evaluation system satisfaction? (evidence from a UK Police Force). Gadjah Mada International Journal of Business, 15(3), p. 231. 
AUTHORS' BACKGROUND

\begin{tabular}{|l|l|l|l|}
\hline \multicolumn{1}{|c|}{ Your Name } & Title* & Research Field & Personal website \\
\hline Ahmed Alrashedi & PhD candidate & Business studies & brunel.ac.uk/people/Maysam-abbod \\
\hline Maysam Abbod & Reader & $\begin{array}{c}\text { Electronic and Computer } \\
\text { Engineering }\end{array}$ & \\
\hline & & & \\
\hline
\end{tabular}

